\title{
Evaluation of treatment outcomes in a 3 years post-graduate orthodontic program using the peer assessment rating (par)
}

\author{
Paloma González-Gil-de-Bernabé ${ }^{1}$, Carlos Bellot-Arcís ${ }^{2}$, José M. Montiel-Company ${ }^{3}$, José L. Gandía-Franco ${ }^{4}$ \\ ${ }^{1}$ Assistant professor. Stomatology Department, Faculty of Medicine and Dentistry, University of Valencia, Spain \\ ${ }^{2} \mathrm{PhD}$, Adjunct Professor. Stomatology Department, Faculty of Medicine and Dentistry, University of Valencia, Spain \\ ${ }^{3}$ PhD. Post-Doctoral Assistant Professor, Stomatology Department, Faculty of Medicine and Dentistry, University of Valencia, \\ Spain \\ ${ }^{4} \mathrm{PhD}$. Tenured Lecturer, Stomatology Department, Faculty of Medicine and Dentistry, University of Valencia. Spain
}

Correspondence:

C/Joan Maragall 32

CP: 07006. Palma de Mallorca

ortopal@yahoo.es

González-Gil-de-Bernabé P, Bellot-Arcís C, Montiel-Company JM, Gandía-Franco JL. Evaluation of treatment outcomes in a 3 years postgraduate orthodontic program using the peer assessment rating (par). $\mathbf{J}$ Clin Exp Dent. 2014;6(4):e364-8. http://www.medicinaoral.com/odo/volumenes/v6i4/jcedv6i4p364.pdf

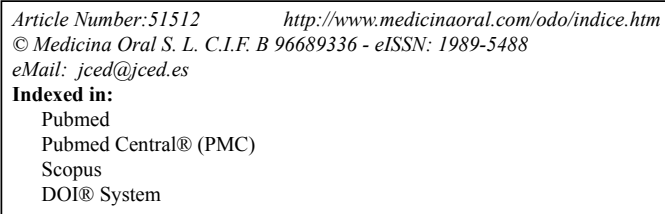

\begin{abstract}
Objectives: To maintain high treatment quality it is important to evaluate orthodontic treatment results using objective methods. Outcome assessments allow private practitioners and university students to evaluate their results and raise the level of treatment outcomes. The aim of this study was to assess the orthodontic treatment outcome in a post-graduate orthodontics program in the University of Valencia (Spain) and to determine whether the treatment outcome is related to several factors as gender, age at start of the treatment, treatment duration, treatment method, extraction-non extraction treatment and cooperation needed.

Material and Methods: A sample of 50 patients treated in the post-graduate clinic was randomly selected. Pretreatment and post-treatment study casts have been assessed by the Peer Assessment Rating (PAR index). The influence of various factors: gender, age at start of the treatment, treatment duration, treatment method, extraction-non extraction treatment, cooperation needed and number of students finishing each case, were statistically analyzed. Results: According to the PAR index, orthodontic treatment reduced the malocclusion in a mean point reduction of 21.4 (CI 95\% 18.7-24.1) and a mean percentage reduction of $80.5 \%$ (CI 95\% 75.9-85.1). The total of the cases improved, $44 \%$ of the patients were in greatly improved category.

Conclusions: None of the variables studied influenced significantly the treatment outcomes regarding the PAR. Based on the general classification criteria of the index, the results showed that the patients received a high standard treatment.
\end{abstract}

Key words: Treatment outcome, orthodontics education, PAR Index. 


\section{Introduction}

To maintain high treatment quality it is important to evaluate orthodontic treatment results continuously, using objectives methods (1). Outcome assessments allow private practitioners and university students to evaluate their results and raise the level of treatment outcomes $(1,2)$. Special importance is to keep the quality of educational in post-graduate clinics high, in order that students are exposed to optimal treatment procedures (3-8). By evaluating the quality of treatments, we evaluate the skills acquired by the students and, of course, the quality of a 3 years post-graduate orthodontic program.

Several indices have been developed to assess the success of treatment, to ensure uniform interpretation and application of criteria (9). The most commonly used to assess orthodontic outcome, is the Peer Assessment Rating Index [PAR]. It is an occlusal index designed to measure how much a patient deviates from normal alignment and occlusion (10).

The PAR components are the upper and lower anterior segments, the upper and lower right and left segments, the overjet, the overbite and the midline. They generate summarize data about the malocclusion and return a numeric value between 0 , corresponding ideal occlusion and 60 near the worst (11). The difference between final PAR and initial PAR reflects the degree of improvement and therefore the success of the treatment $(8,12)$.

The PAR index has been used widely for evaluating the effects of treatment in a variety of circumstances: treatment with fixed and removable appliances (3), to compare treatment in orthodontics schools and private practices $(3,4,7,8)$, results from different type of initial malocclusion (13) also in the first phase treatments (14) and in the assessment of orthognatic surgery outcome (15).

This index has been shown to have good intra and interexaminer reliability and offers standardization in assessing the outcome of orthodontic treatment in three categories: Worse-no different [there is not reduction in the initial PAR score or less than a 30\%], improved [greater than or equal to $30 \%$ reduction in the PAR score], greatly improved [the total PAR score is reduced more than 22 points or greater or equal to $70 \%$ ] (12).

To allocated the outcome in a high standard treatment from the total patients, according to the general classification criteria of the index, the sample should have a higher percentage than $70 \%$ cases showing improvement, more than $40 \%$ should be of great improvement and cases with negligible minimum improvement or worse should be a maximum of $5 \%$.

The objectives of this retrospective study were:

- To evaluate the quality of treatment performed in a post-graduate orthodontic program in the University of Valencia [Spain] using the PAR index.

- To determine whether the treatment outcome [change in PAR] is related to the following factors: gender, age at start of treatment, duration of treatment, treatment technique, extractions, cooperation needed and number of students treating a case.

\section{Material and Methods}

The sample for this study was obtained from the patients treated with fixed appliances during the last ten years at the Master of Orthodontics at the Dental School of the University of Valencia. Fifty-five were randomly selected from a total of 440 cases in retention phase, five of them were excluded because they lacked completed records. The study obtained the approval, from the Institutional Review Board from the Stomatology Department [University of Valencia, Spain].

The following information was noted in each case from the records: gender, date of birth, date treatment started, date treatment finished, age at the start of treatment, duration of treatment, treatment technique [Standard, Bidimensional, MBT, Tip-edge, Smart-clip], extracted teeth, cooperation needed from the patient, and number of students treating each case. The PAR score was obtained from pre-treatment and post-treatment study models and its components were: upper labial segment alignment, lower labial segment alignment, buccal segment relationship, overbite, overjet and midline.

The error of the method for recording of the PAR index was evaluated from double measurements, one month interval by the same examiner. Intraexaminer agreement was analyzed by the Intraclass Correlation Coefficient [ICC] in order to evaluate the validity of the method.

A further measurement of $20 \%$ of the cases, randomly selected, was evaluated for another examiner, an orthodontist calibrated at the Occlusal Index Calibration Course held by Dr. Richmond, author of the PAR index (11). Interexaminer reliability was also evaluated with the Intraclass Correlation Coefficient [ICC].

The outcome was assessed using the numerical and percentage reduction weighted PAR score.

To estimate the relationship between the variables and the PAR reduction and percentage change rates, nonparametric tests were made. The Mann Withney's $U$ test procedure was applied in the categorical variables with a $p<0.05$ significance level.

Pearson's Correlation Coefficient was computed to assess the linear relationships between score reduction [total points and percentage] and the numeric variables evaluated [age at start treatment and time of treatment]. All statistical analysis was carried out using the Statistical Package for Social Sciences for Windows software, version 21 [SPSS v. 21].

\section{Results}

Out of the total sample of 50 patients, $38 \%$ were men $[n=19]$ and $62 \%$ were women $[n=31]$. The average pre- 
treatment age was 17.2 [CI 95\% 14.4-20.0]. The average treatment duration was 2.4 years [CI 95\% 2.1-2.7].

The treatment technique was $42 \%$ Standard, $18 \%$ Bidimensional, 14\% MBT, 18\% Tip-Edge and 8\% Smartclip. Extraction treatment was performed on $20 \%$ of patients. The number of students taking part in each case was: $56 \%$ one student per patient, $44 \%$ two or three. The need for cooperation by the patient was required in $78 \%$ of cases.

The pre-treatment PAR index mean was 26.3 [CI 23.6$29.1]$ and the post-treatment PAR index mean was 4.9 [CI 3.6-6.3]. The mean value of the changes PAR was 21.4 [CI 18.7-24.1] and the percentages reduction was $80.5 \%$ [CI 75.9-85.1].

None of the categorical variables studied [gender, technique, extractions, number of master students and need for patient's collaboration] influenced significantly the treatment outcomes regarding the PAR (Table 1).

In the quantitative variables we found statistical negative correlation between average treatment duration and change in PAR percentage, but this correlation was weak [Pearson $=-0.28]$. Treatment duration had also weak and negative correlation with age at the beginning of treatment [Pearson $=-0.30]$.

To assess the success in our sample, figure 1 shows the degree of improvement classified into the following categories: 1 . No improvement, $0 \%$ of the cases; 2 . Im-

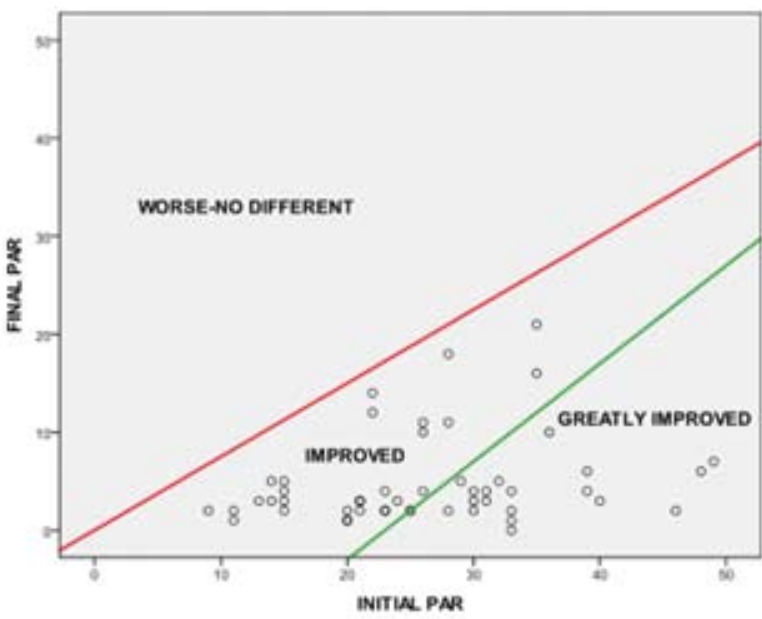

Fig. 1. Pre-treatment and post-treatment PAR scores distribution in different categories.

provement , $56 \%$ of the cases , 3. Greatly improved, 44 $\%$ of the cases.

The Intraclass Correlation Coefficient showed excellent intra-examiner reliability: 0.98 for the initial and final PAR measurements. Excellent Inter-examiner agreement validity resulted [0.87] for the initial PAR and 0.89 for the final PAR, compared with de Gold Standard.

Table 1. Mean PAR distribution related with categorical variables: gender, technique, extractions, number of Master students and need for patient's collaboration. Statistical nonparametric test applied. *Significant differences $(\mathrm{p}<0.05)$ in Man Whitney's test. CI-95\% Confindence Interval.

\begin{tabular}{|c|c|c|c|c|c|c|c|}
\hline & & $\begin{array}{l}\text { Initial PAR } \\
\text { Mean } \\
\text { (CI 95\%) }\end{array}$ & $\begin{array}{l}\text { Final PAR } \\
\text { Mean } \\
\text { (CI 95\%) }\end{array}$ & $\begin{array}{l}\text { Change in } \\
\text { PAR \% } \\
\text { Mean } \\
\text { (CI 95\%) } \\
\end{array}$ & \begin{tabular}{|l|} 
Man \\
Whitney's \\
U test \\
P value \\
\end{tabular} & $\begin{array}{l}\text { Change in } \\
\text { PAR score } \\
\text { Mean } \\
\text { (CI 95\%) }\end{array}$ & \begin{tabular}{|l} 
Man \\
Whitney's U \\
test \\
P value \\
\end{tabular} \\
\hline Gender & $\begin{array}{l}\text { Male } \\
(n=19)\end{array}$ & $\begin{array}{l}28.8 \\
(23.8-37.8) \\
\end{array}$ & \begin{tabular}{|l|}
5.1 \\
$(2.5-7.6)$ \\
\end{tabular} & \begin{tabular}{|l|}
81.7 \\
$(73.9-89.4)$ \\
\end{tabular} & $p=0.63$ & $\begin{array}{l}23.7 \\
(18.6-28.8) \\
\end{array}$ & $p=0.23$ \\
\hline & $\begin{array}{l}\text { Female } \\
(n=31)\end{array}$ & $\begin{array}{l}24.8 \\
(21.5-28.1)\end{array}$ & $\begin{array}{l}4.8 \\
(3.3-6.4)\end{array}$ & $\begin{array}{l}79.8 \\
(73.8-95.9)\end{array}$ & & $\begin{array}{l}19.9 \\
(16.7-23.1)\end{array}$ & \\
\hline Technique & $\begin{array}{l}\text { Standard } \\
(\mathrm{n}=21)\end{array}$ & $\begin{array}{l}28.5 \\
(24.2-32.8)\end{array}$ & $\begin{array}{l}6.2 \\
(3.8-8.6) \\
\end{array}$ & $\begin{array}{l}77.7 \\
(69.8-85.6) \\
\end{array}$ & $\mathrm{p}=0.17$ & $\begin{array}{l}22.3 \\
(17.8-26.7) \\
\end{array}$ & $p=0.67$ \\
\hline & $\begin{array}{l}\text { Others } \\
(\mathrm{n}=29)\end{array}$ & $\begin{array}{l}24.7 \\
(21.1-28.3)\end{array}$ & $\begin{array}{l}4.0 \\
(2.5-5.5) \\
\end{array}$ & $\begin{array}{l}82.5 \\
(76.7-88.3) \\
\end{array}$ & & $\begin{array}{l}20.7 \\
(17.1-24.3) \\
\end{array}$ & \\
\hline Extractions & $\begin{array}{l}\text { No } \\
(\mathrm{n}=40)\end{array}$ & $\begin{array}{l}25.9 \\
(23.2-28.7) \\
\end{array}$ & \begin{tabular}{|l|}
5.1 \\
$(3.6-6.5)$ \\
\end{tabular} & $\begin{array}{l}79.9 \\
(74.8-85.1) \\
\end{array}$ & $p=0.57$ & $\begin{array}{l}20.9 \\
(18.1-23.6)\end{array}$ & $p=0.72$ \\
\hline & $\begin{array}{l}\text { Yes } \\
(\mathrm{n}=10)\end{array}$ & $\begin{array}{l}27.7 \\
(18.2-37.2)\end{array}$ & $\begin{array}{l}4.5 \\
(0.9-8.1)\end{array}$ & $\begin{array}{l}82.7 \\
(70.3-95.1) \\
\end{array}$ & & $\begin{array}{l}23.2 \\
(13.7-32.6)\end{array}$ & \\
\hline $\begin{array}{l}\text { Number of Mas- } \\
\text { ter students }\end{array}$ & $\begin{array}{l}1 \\
(n=28)\end{array}$ & $\begin{array}{l}25.2 \\
(21.5-28.9)\end{array}$ & $\begin{array}{l}4.9 \\
(2.8-6.9)\end{array}$ & $\begin{array}{l}79.4 \\
(72.0-86.8) \\
\end{array}$ & $p=0.77$ & $\begin{array}{l}20.3 \\
(16.3-24.2)\end{array}$ & $p=0.35$ \\
\hline & $\begin{array}{l}2 \text { or } 3 \\
(n=22)\end{array}$ & $\begin{array}{l}27.7 \\
(23.4-31.9) \\
\end{array}$ & $\begin{array}{l}4.9 \\
(3.3-6.6)\end{array}$ & $\begin{array}{l}81.9 \\
(76.7-87.2) \\
\end{array}$ & & $\begin{array}{l}22.7 \\
(18.9-26.7) \\
\end{array}$ & \\
\hline $\begin{array}{l}\text { Need for } \\
\text { Patient's collabo- }\end{array}$ & $\begin{array}{l}\text { No } \\
(\mathrm{n}=11)\end{array}$ & $\begin{array}{l}24.2 \\
(18.9-29.4) \\
\end{array}$ & $\begin{array}{l}5.5 \\
(1.4-9.7) \\
\end{array}$ & $\begin{array}{l}77.2 \\
(63.0-01.3) \\
\end{array}$ & $\mathrm{p}=0.82$ & $\begin{array}{l}18.6 \\
(13.1-24.1) \\
\end{array}$ & $\mathrm{p}=0.33$ \\
\hline ration & $\begin{array}{l}\text { Yes } \\
(n=39)\end{array}$ & $\begin{array}{l}26.9 \\
(23.7-30.2)\end{array}$ & $\begin{array}{l}4.8 \\
(3.4-6.1) \\
\end{array}$ & $\begin{array}{l}81.5 \\
(76.7-86.2)\end{array}$ & & $\begin{array}{l}22.2 \\
(18.9-25.4)\end{array}$ & \\
\hline
\end{tabular}




\section{Discussion}

Our sample, in relation to other authors who have conducted the study in orthodontic schools, is quite similar in the percentage of men and women distribution $(8,16)$. The results of the change and percentage PAR obtained does not vary with the sex of the patient in accordance with other researchers.

Although the average age at the start of the treatment in our sample was 17 years, higher than in other studies $(2,5,16), 60 \%$ of our cases treatment was initiated between ten and fifteen years old. We found no association between starting age and treatment outcome.

The average treatment duration was 28 months and it agrees with other authors who carried out similar studies $(4,6,17)$. We found statistical negative correlation between average treatment duration and change in PAR percentage, but this correlation was weak [Pearson $=-0.28]$. Some authors have found that the longer treatment produces worse outcomes $(2,6)$, and others get totally opposite results (18). We cannot forget the risk of long-term treatment in terms of iatrogenic and we must distinguish cases that drag on for lack of cooperation from those who do it for a better finish.

Analyzed in our study the relationship of the results obtained and the different treatment techniques used, we found no statistical significance like others authors $(19,20)$ but we could not compare with them because they use other indices to assess the outcome of treatment and only one of them analyzed two matching techniques (20).

The number of students taking part in the treatment did not influence the result in terms of quality of treatment outcomes as the study conducted in three orthodontic clinics by Cook et al. (7). Noted that the duration of Master study last for three years, so that, students can finish the largest number of cases and improve their training.

Another variable considered was the presence of extractions in treatment. Our percentage of extractions was $20 \%$ of cases, less than in other samples of random selection $(6,16)$. We found no statistical relationship like other results consulted $(21,22)$.

The need for patient's collaboration was also analyzed in our study. It was necessary in $80 \%$ of cases without presenting statistical relationship with the results. Only one author associated this variable with treatment duration, but not with the treatment outcome (6).

In making our measurements, the findings show a high degree of predictability in agreement with other authors $(2,9)$. The validation of our measures using a Gold Standard shows a very high concordance, somewhat higher than those found by other authors (22-25), perhaps due to both the author and the Gold Standard, have been studied at the same research clinic which may lead to unified observation criteria.

The quantitative variable for the initial PAR index was an average of 26.3 PAR similar to other authors $(2,3,8,17)$. The quantitative average final PAR obtained in our study was 4.9 , also similar to other studies $(2,4)$.

The change in value of the PAR and the percentage change PAR were respectively 21.4 and $80.5 \%$, obtained from the values initial and final PAR, allow us to compare with clinical training in orthodontics and see outcome studies percentage reduction between $81 \%$ and $70.7 \%$ on similar samples $(2,24)$.

The limitations of the study were the size of the sample $[n=50]$, but we should consider that it is enough to achieve the proposed objectives. Moreover, we collected a random sample representative of the whole cases treated at the post-graduate orthodontic program. Regarding the validity of the method, high values were obtained in both, the intraexaminer and interexaminer agreement. The PAR index allows us to classify the overall level of treatment and rated data of the PAR value change and percentage change in varying degrees of improvement. That gives a set value to the results. In our sample, to sort the data, the results are clear and conclusive: all the cases improved and the $44 \%$ with great improvement. Others authors showed a $4 \%$ worsening and $55 \%$ great improvement (7) and 3\% worsening and 50\% big improvement (17).

According to the general classification criteria of the index, to consider a high standard of treatment, the sample should have a higher percentage than $70 \%$ cases showing improvement and more than $40 \%$ should be of great improvement and cases with negligible minimum improvement or worse should be a maximum of $5 \%$. Our results clearly demonstrate meeting the criteria required of the high standard rating: 100\% improved and from this total, $44 \%$ with great improvement.

By evaluating the quality of treatments performed by students using the PAR index, we evaluate the skills acquired by the students and, of course, the quality of a 3 years post-graduate orthodontic program.

\section{References}

1. de Winter FR. How good are you? Am J Orthod and Dentofacial Orthop. 2011;140:752.

2. Dyken RA, Sadowsky PL, Hurst D. Orthodontic outcomes assessment using the peer assessment rating index. Angle Orthod. 2001;71:164-9.

3. Firestone AR, Häsler RU, Ingervall B. Treatment results in dental school orthodontic patients in 1983 and 1993. Angle Orthod. 1999;69:19-26.

4. Willems G, Heidbüchel R, Verdonck A, Carels C. Treatment and standard evaluation using the Peer Assessment Rating Index. Clin Oral Investig. 2001;5:57-62.

5. Yang-Powers LC, Sadowsky C, Rosenstein S, BeGole EA. Treatment outcome in a graduate orthodontic clinic using the American Board of Orthodontics grading system. Am J Orthod Dentofacial Orthop. 2002; $122: 451-5$.

6. Pinskaya YB, Hsieh TJ, Roberts WE, Hartsfield JK. Comprehensive clinical evaluation as an outcome assessment for a graduate orthodontics program. Am J Orthod Dentofacial Orthop. 2004;126:533-43. 
7. Cook DR, Harris EF, Vaden JL. Comparison of university and private-practice orthodontic treatment outcomes with the American Board of Orthodontics objective grading system. Am J Orthod Dentofacial Orthop. 2005;127:707-12.

8. Bernas AJ, Banting DW, Short LL. Effectiveness of phase I orthodontic treatment in an undergraduate teaching clinic. J Dent Educ. 2007;71:1179-86.

9. Bergström K, Halling A. Comparison of three indices in evaluation of orthodontic treatment outcome. Acta Odontol Scand. 1997;55:3643.

10. Shaw WC, Richmond S, O'Brien KD. The use of occlusal indices: a European perspective. Am J Orthod Dentofacial Orthop. 1995;107:1 10.

11. Richmond S, Shaw WC, O'Brien KD, Buchanan IB, Jones R, Stephens CD, Roberts CT, Andrews M. The development of the PAR Index (Peer Assessment Rating): reliability and validity. Eur J Orthod. 1992;14:125-39.

12. Richmond S, Shaw WC, Roberts CT, Andrews M. The PAR Index (Peer Assessment Rating): methods to determine outcome of orthodontic treatment in terms of improvement and standards. Eur J Orthod. 1992;14:180-7.

13. Freitas KM, Freitas DS, Valarelli FP, Freitas MR, Janson G. PAR evaluation of treated Class I extraction patients. Angle Orthod. 2008;78:270-4

14. Pangrazio-Kulbersh V, Kaczynski R, Shunock M. Early treatment outcome assessed by the Peer Assessment Rating index. Am J Orthod Dentofacial Orthop. 1999;115:544-50.

15. Nurminen L, Pietilä T, Vinkka-Puhakka H. Motivation for and satisfaction with orthodontic-surgical treatment: a retrospective study of 28 patients. Eur J Orthod. 1999;21:79-87.

16. Campbell CL, Roberts WE, Hartsfield JK Jr, Qi R. Treatment outcomes in a graduate orthodontic clinic for cases defined by the American Board of Orthodontics malocclusion categories. Am J Orthod Dentofacial Orthop. 2007;132:822-9.

17. Onyeaso CO, Begole EA. Orthodontic treatment--improvement and standards using the peer assessment rating index. Angle Orthod. 2006;76:260-4.
18. Turbill EA, Richmond S, Wright JL. The time-factor in orthodontics: what influences the duration of treatments in National Health Service practices? Community Dent Oral Epidemiol. 2001;29:62-72.

19. Vu CQ, Roberts WE, Hartsfield JK Jr, Ofner S. Treatment complexity index for assessing the relationship of treatment duration and outcomes in a graduate orthodontics clinic. Am J Orthod Dentofacial Orthop. 2008;133:1-13.

20. Brown PN, Kulbersh R, Kaczynski R. Clinical outcomes assessment of consecutively finished patients in a 24-month orthodontic residency: a 5-year perspective. Am J Orthod Dentofacial Orthop. 2011;139:665-8.

21. Holman JK, Hans MG, Nelson S, Powers MP. An assessment of extraction versus nonextraction orthodontic treatment using the peer assessment rating (PAR) index. Angle Orthod. 1998;68:527-34.

22. Firestone AR, Beck FM, Beglin FM, Vig KW. Validity of the Index of Complexity, Outcome, and Need (ICON) in determining orthodontic treatment need. Angle Orthod. 2002;72:15-20.

23. Birkeland K, Furevik J, Bøe OE, Wisth PJ. Evaluation of treatment and post-treatment changes by the PAR Index. Eur J Orthod. 1997;19:279-88.

24. Deguchi T, Honjo T, Fukunaga T, Miyawaki S, Roberts WE, Takano-Yamamoto T. Clinical assessment of orthodontic outcomes with the peer assessment rating, discrepancy index, objective grading system, and comprehensive clinical assessment. Am J Orthod Dentofacial Orthop. $2005 ; 127: 434-43$.

25. Arruda AO. Occlusal indexes as judged by subjective opinions. Am J Orthod Dentofacial Orthop. 2008;134:671-5.

Acknowledgements

Text of Acknowledgement.

\section{Conflict of Interest}

The authors declare that they have no conflict of interest. 